\title{
Pengalaman Keluarga Berkomunikasi dengan Lansia di Wilayah Kerja Puskesmas Pemenang Kabupaten Lombok Utara
}

\author{
Lalu Bahrudin ${ }^{1(\mathrm{CA})}$ \\ ${ }^{1(\mathrm{CA})}$ Program Studi Magister Kesehatan Fakultas Kesehatan Universitas Qamarul Huda Badaruddin \\ Jln. H. Badruddin Bagu - Pringgarata - Lombok Tengah, Indonesia; \\ e-mail: drlalubahrudin@gmail.com, (Corresponding Author)
}

\begin{abstract}
The number of elderly continues to increase in line with advances in the health sector accompanied by an increase in life expectancy and a decrease in mortality. Various problems in the life of the elderly in Indonesia, such as health problems, social welfare and the absence of adequate income. This causes many families to no longer respect the elderly as parents and treat them harshly, both physically and verbally, in the form of using harsh language, curses and curses on the elderly. This study uses a qualitative method with a phenomenological approach, to explore family experiences communicating with the elderly at home in the Work Area of the Puskesmas Pemenang, North Lombok. The results showed that families have good experiences when communicating with the elderly, for elderly families are parents who are role models, the family always supports the elderly to communicate and interact with family members at home, regardless of the various obstacles and challenges.
\end{abstract}

\section{Keywords : Elderly; Family; Communication}

\begin{abstract}
ABSTRAK
Jumlah lansia terus mengalami peningkatan seiring kemajuan bidang kesehatan yang disertai meningkatnya angka harapan hidup dan menurunnya angka kematian. Berbagai permasalahan dalam kehidupan lansia di Indonesia, seperti masalah kesehatan, kesejahteraan sosial serta ketiadaan penghasilan yang memadai. Hal tersebut membuat banyak keluarga yang tidak lagi menghormati lansia sebagai orang tua serta memperlakukan lansia dengan kasar, baik secara fisik maupun secara verbal berupa pengagunaan bahasa yang kasar, umpatan-umpatan serta makian pada lansia. penelitian ini menggunakan metode kualitatif dengan pendekatan fenomenologis, untuk menggali pengalaman keluarga berkomunikasi dengan lansia di rumah di Wilayah Kerja Puskesmas Pemenang Lombok Utara. Hasil penelitian menunjukan keluarga mempunyai pengalaman yang baik saat berkomunikasi dengan lansia, bagi keluarga lansia merupakan orang tua yang menjadi suri tauladan, keluarga selalu mendukung lansia untuk berkomunikasi dan berinteraksi dengan anggota keluarga di rumah, terlepas dari berbagai hambatan dan tantangan yang ada.
\end{abstract}

\section{Kata Kunci : Lansia; Keluarga; Komunikasi}

\section{PENDAHULUAN}

Lanjut usia (lansia) adalah seseorang yang telah mencapai usia 60 (enam puluh) tahun ke atas (Maylasari et al., 2019). Jumlah lansia terus mengalami peningkatan seiring kemajuan bidang kesehatan yang disertai meningkatnya angka harapan hidup dan menurunnya angka kematian (Muhtar \& Aniharyati, 2019). Seiring dengan bertambahnya usia lansia berbagai konsekwensi dan permasalahan kesehatan akan dihadapi oleh lansia sebagai akibat proses penuaan (Backonja et al., 2012). 
Semakin bertambahnya umur lansia mengakibatkan berbagai perubahan fungsi tubuh secara alamiah (Wulandari \& Marliana, 2019). Permasalah yang timbul akibat bertambahnya jumlah lansia tidak hanya terkait kondisi fisik lansia itu sendiri tapi juga berpotensi menimbulkan permasalahan terkait kehidupan keluarga dan masyarakat seperti meningkatnya beban kebutuhan keluarga secara ekonomi, sosial psikologis serta pelayanan kesehatan dan rekreatif (Muhtar \& Aniharyati, 2019). Hal ini karena keluarga merupakan pusat pertumbuhan dan perkembangan individu, sehingga keluarga menjadi salah satu aspek terpenting dari keperawatan lansia melalui pendekatan asuhan keperawatan keluarga (Muhtar \& A. Haris, 2016).

Penduduk lanjut usia merupakan bagian dari anggota keluarga dan anggota masyarakat yang semakin bertambah jumlahnya sejalan dengan peningkatan usia harapan hidup Sebagian besar lansia tinggal bersama keluarga, sebagaimana lazimnya struktur keluarga yang ada di Indonesia sebagian besar adalah berupa keluarga besar (Extended Family) yang anggotanya terdiri dari ayah, ibu, anak dan kekek / nenek (Muhtar, Haris, \& Aniharyati, 2019). Disamping itu keluarga merasa bahagia dengan kehadiran lansia (orang tua) di tengah-tengah mereka walaupuan lansia memiliki masalah kesehatan seperti keterbatasan fisik, mental dan sosial (Muhtar, 2013).

Seiring perkembangan zaman yang semakin modern, terjadi pergeseran nilai sosial budaya di masyarakat, salah satunya adanya perubahan sikap masyarakat modern yang kurang perhatian terhadap lansia dengan sifat masyarakat yang lebih mementingkan ususan pribadi dan golongan serta cenderung mengabaikan lingkungan di sekitarnya termasuk kelompok lansia yang sering diabaikan (Prabasari, Juwita, \& Maryuti, 2017). Disamping itu keberadaan lansia dipandang remeh sebagai beban bagi keluarga maupun masyarakat di sekitarnya (Wulandari \& Marliana, 2019). Pandangan seperti ini muncul karena masyarakat masih melihat lansia sebagai individu yang tidak produktif, memiliki tingkat ketergantungan yang tinggi serta sering sakit-sakitan (Arrum, Herawati, \& Dwipa, 2020). Namun demikan pandangan seperti itu belum tentu benar, sebab masih banyak lansia dengan usia 60 tahun ke atas yang masih produktif, mampu berperan aktif dalam kehidupan keluarga dan masyarakat sekitarnya (Prabasari et al., 2017).

Berbagai permasalahan dalam kehidupan lansia di Indonesia, seperti masalah kesehatan, kesejahteraan sosial serta ketiadaan pekerjaan maupun penghasilan yang memadai, terutama bagi penduduk lansia yang waktu mudanya lebih banyak menganggur, tidak berpendidikan serta tidak memiliki kompetensi dan keterampilan tertentu (Maylasari et al., 2019). Hal tersebut membuat banyak keluarga yang tidak lagi menghormati lansia sebagai orang tua serta memperlakukan lansia dengan kasar, baik secara fisik maupun secara verbal berupa pengagunaan bahasa yang kasar, umpatan-umpatan serta makian pada lansia (Muhtar \& Aniharyati, 2019). Perlakuan keluarga yang kasar terhadap lansia bisa terjadi akibat keluarga yang kurang memahami tentang komunikasi dengan lansia atau cara keluarga yang salah dalam berkomunikasi dengan lansia (Taviyanda \& Aris Siswanto, 2016).

Sudah sewajarnya lansia mendapat perhatian dari anggota keluarga dan masyarakat dengan tetap mengupayakan agar mereka mandiri dalam menjalani aktivitas sehari-hari demi menjaga kesehatan dan kebugarannya (Wang \& Dolezel, 2016), selanjutnya keluarga dan masyarakat berkewajiban menjaga serta mengantarkan lansia untuk hidup bahagia di akhir hidupnya melalui interaksi sosial dengan orang-orang 
dan lingkungan sekitarnya (Muhtar \& A. Haris, 2016). Oleh karena itu, penelitian ini ingin mengetahui lebih dalam lagi tentang pengalaman keluarga dalam berkomunikasi dengan lansia di Wilayah Kerja Puskesmas Pemenang Kabupaten Lombok Utara. Hasil penelitian diharapkan dapat memberikan informasi tentang peran serta keluarga dalam pemenuhan kebutuhan komunikasi dan interaksi sosial lansia di rumah sebagai salah satu aspek peningkatan kesehatan lansia (Tenforde, Jain, \& Hickner, 2011).

\section{METODE}

Penelitian ini menggunakan metode kualitatif dengan pendekatan fenomenologis, untuk menggali pengalaman keluarga dalam berkomunikasi dengan lansia di rumah di Wilayah Kerja Puskesmas Pemenang Lombok Utara. Pengumpulan data menggunakan wawancara mendalam (indepht interview), alat yang digunakan adalah peneliti sendiri dan instrumen penelitian berupa pedoman wawancara dan dibantu dengan alat tulis, buku catatan dan tape recorder. Data yang terkumpul di analisis dengan cara triangulasi untuk menarik kesimpulan berdasarkan subtopik dan topik bahasan.

\section{HASIL}

\section{Pandangan keluarga tentang komunikasi dengan lansia}

\section{a. Pandangan keluarga terhadap lansia}

Hasil penelitian dengan metode wawancara, responden mengatakan bahwa mereka memandang lansia sebagai orang tua, sebagaimana pendapat responden berikut :

...orangnya baik....sebagai orang tua...saya sangat menghormatinya. (R1)

...lansia itu orang tua.....sudah berumur lebihlah... (R2)

...orang tua kita....tinggal sama kita...(R3)

...umurnya sudah tua... saya memandang mereka sebagai orang tua... (R4)

...orangnya baik, rasa kasih sayangnya sangat besar ....saya menghormati mereka sebagai orang tua. (R5)

Beberapa responden juga mengatakan bahwa lansia itu orang yang baik dan memiliki rasa kasih sayang yang sangat besar sehinga mereka patut dihormati, sebagaimana pendapat responden berikut :

...orangnya baik....sebagai orang tua...saya sangat menghormatinya. (R1)

...orangnya baik, rasa kasih sayangnya sangat besar ....saya menghormati mereka sebagai orang tua. (R5)

\section{b. Perasaan keluarga berkomunikasi dengan lansia}

Responden memberikan pendapat yang beragam mengenai perasaan mereka saat berkomunikasi dengan lansia, ada yang merasa senang karena lansia suka memberi nasehat, ada juga yang merasa bosan, susah, dan jengkel karena lansia sering tidak nyambung, banyak ngomong dan pembicaraannya suka ngalor ngidul, sebagaimana pendapat responden berikut : 
....Saya merasa senang...suka sekali kasih nasehat....saya juga merasa bosan.. (R1)

....kadang senang, kadang susah....susah-susah gampang....sering tidak nyambung...ngomongnya banyak... (R2)

Susah mas...orangnya cerewet, tidak mau diatur, saya rasakan seperti ngomong sama anak kecil... (R3)

....kadang-kadang jengkel, kadang senang, membosankan.... (R4)

....rasanya menjengelkan....sering tidak nyambung....pembicaraanya suka ngalor ngidul... (R5)

\section{Hambatan yang dialami keluarga dalam komunikasi dengan lansia}

Hambatan yang sering dialami keluarga sewaktu berkomunikasi dengan lansia adalah faktor pendengaran lansia yang sudah berkurang sehingga pembicaraan sering tidak nyambung, disamping itu lansia juga sering lupa sehingga suka mengulang-ulang pembicaraan yang sama, sebagaimana pendapat responden berikut :

....pendengaran si mbah yang kurang....sering lupa... (RI)

....suka menguasai pembicaraan.... sering tidak nyambung... (R2)

....susah sekali diatur...harus mengulang-ulang kalo bicara... pendengaranya sudah berkurang.... (R3)

....sudah berkurang pendengaranya....suka tidak nyambung....cepat marah.... (R4)

....pembicaraanya suka nggak nyambung....pendengaranya yang sudah berkurang, orangnya juga sudah mulai pikun mas... (R5)

Hambatan lain yang dialami responden yaitu lansia suka menguasai pembicaraan dan mereka cepat marah, sebagaimana pendapat responden berikut :

....suka menguasai pembicaraan....sering tidak nyambung... (R2)

....sudah berkurang pendengaranya....suka tidak nyambung....cepat marah.... (R4)

\section{Upaya keluarga meningkatkan kelancaran komunikasi dengan lansia}

\section{a. Upaya mengurangi hambatan komunikasi}

berbagai upaya keluarga dalam mengurangi hambatan saat berkomunikasi dengan lansia yaitu berbicara pelan, dengan suara yang keras dan tegas, mengulang pembicaraan sampai lansia mengerti, menjaga jarak saat berbicara dengan duduk berdekatan atau bersampingan dengan lansia, serta banyak bersabar dan tetap menghormati lansia sebagai orang tua, sebagaimana pendapat responden berikut :

....bicaranya lebih keras lagi...duduk berdekatan .... ngomong saya ulang.... (R1)

....harus banyak bersabar...pembicaraan kita ulang-ulang... (R2)

....menarik tangannya ....ngomong harus keras didekat telinganya biar dia bisa mendengar... (R3) 
....ngomong dengan suara yang agak keras, berbicara tidak terlalu cepat ...menghormati mereka sebagai orang tua.... (R4)

....duduk bersampingan....bicara dengan suara yang agak keras, bicara berulang-ulang... (R5)

\section{b. Penunjang kalancaran komunikasi dengan lansia}

Berdasarkan wawancara mendalam didapatkan bahwa responden mengatakan beberapa hal yang dapat menunjang komunikasi dengan lansia yaitu lansia yang memulai pembicaraan, perasaan lansia yang lagi senang, suasana lingkungan yang menunjang, ngobrol berduaan dengan lansia, duduk berhadapan dengan lansia serta kesabaran saat berkomunikasi dengan lansia, sebagaimana pendapat responden berikut :

....kalo mbah nya lagi senang....kalo mbahnya lagi pingin ngobrol....dirumah lagi sepi... (RI) ....ngobrol berdua saja ....sering mengulang-ulang pertanyaan....saya duduk berhadapan... $(R 2)$

....berhadap-hadapan, dengan suara yang keras, kadang saya harus mengulang-ulang pertanyaan.... (R3)

....tetap sopan sama orang tua, saat berbicara kita bersikap rendah diri, duduk berhadapan ...harus banyak bersabar... (R4)

....orang tua yang memulai pembicaraan....banyak bersabar... (R5)

\section{PEMBAHASAN}

Pengalaman keluarga dalam berkomunikasi dengan lansia yang meliputi : pandangan keluarga terhadap lansia, perasaan keluarga dalam berkumunikasi dengan lansia, hambatan yang dialami keluarga dalam berkomunikasi dengan lansia, upaya keluarga mengurangi hambatan komunikasi serta penunjang kelancaran komunikasi dengan lansia cukup mewakili beberapa teori yang sudah ada.

Agar komunikasi berhasil secara efektif, diperlukan beberapa syarat yang disebut "The Seven C's of Communication" yaitu : Credibility (kredibilitas), keberadaan penyampai pesan diakui dan dapat dipercaya oleh penerima pesan. Context (kontek), situasi dan kondisi tempat berlansung komunikasi relevan dengan keadaan si penerima pesan. Content (isi), materi arau isi pesan yang disampaikan mempunyai arti penting bagi si penerima. Clarity (kejelasan), pesan yang disampaikan oleh pemberi pesan dapat diterima dan dimengerti oleh si penerima. Continuity and consistency (kontinuitas dan konsistensi), pesan yang disampaikan konsisten dan berkesinambungan dan tidak menyimpang dari topik pembicaraan. Channel (saluran) adanya saluran yang digunakan dalam proses komunikasi. Capability of the audience (kemampuan sasaran), pesan yang disampaikan sesuai dengan tingkat penerimaan sasaran, mudah diterima dan tidak sulit dipahami (Ellis \& Abbott, 2017).

Banyak faktor yang mempengaruhi proses komunikasi, faktor-faktor tersebut dapat dibagi menjadi faktor penunjang dan faktor penghambat. Salah satu faktor penunjang yaitu pemahaman atau pengetahuan serta pengalaman dari pembawa pesan. Sementara faktor yang menghambat komunkasi yaitu : pembawa pesan tidak menguasai isi pesan yang disampaikan, kurangnya pengalaman dalam penyampaian pesan penampilan yang kurang meyakinkan, pesan yang disampaikan kurang jelas atau mengandung makna 
ganda, media yang digunakan tidak sesuai dengan topik permasalahan yang disampaikan, pengetahuan penerima pesan terlalu rendah sehingga kurang mampu mencerna pesan yang disampaikan serta lingkungan tempat komunikasi berlangsung terlalu bising sehingga pesan yang disampaikan tidak jelas (Ellis \& Abbott, 2017).

\section{KESIMPULAN}

Keluarga mempunyai pengalaman yang baik saat berkomunikasi dengan lansia, bagi keluarga lansia merupakan orang tua yang menjadi suri tauladan, keluarga selalu mendukung lansia untuk berkomunikasi dan berinteraksi dengan anggota keluarga di rumah, terlepas dari berbagai hambatan dan tantangan yang ada. Upaya keluarga untuk menunjang kelancaran berkomunikasi dengan lansia antara lain memberi kesempatan lansia yang memulai pembicaraan, perasaan lansia yang lagi senang, susana lingkungan yang kondusif, ngobrol berduaan dengan lansia, duduk berhadapan dengan lansia serta kesabaran saat berkomunikasi dengan lansia.

\section{DAFTAR PUSTAKA}

Arrum, R. K., Herawati, D. M. D., \& Dwipa, L. (2020). Nutritional Intake And Affecting Factors of Edelry People Living at Nursing Home. Jurnal Kesehatan Prima, 8(1), 155-165.

Backonja, U., Kim, K., Casper, G. R., Patton, T., Ramly, E., \& Brennan, P. F. (2012). Observations of daily living: putting the "personal" in personal health records. In NI 2012: 11th International Congress on Nursing Informatics, June 23-27, 2012, Montreal, Canada. (Vol. 2012). American Medical Informatics Association.

Ellis, P., \& Abbott, J. (2017). Communication at the heart of leadership: the seven Cs. Journal of Kidney Care, 2(3), 182-183. https://doi.org/10.12968/jokc.2017.2.3.182

Maylasari, I., Rachmawati, Y., Wilson, H., Nugroho, S. W., Sulistyowati, N. P., \& Dewi, F. W. R. (2019). Statistik Penduduk Lanjut Usia di Indonesia 2019. Badan Pusat Statistik. Jakarta.

Muhtar. (2013). Pemberdayaan Keluarga Dalam Peningkatan Self Efficacy Dan Self Care Activity Keluarga Dan Penderita Tb Paru (Family Empowerment in Increasing Self-Effi cacy and Self-Care Activity of Family and Patients with Pulmonary Tb). Jurnal Ners (Vol. 8). https://doi.org/http://dx.doi.org/10.20473/jn.v8i2.3826

Muhtar, \& A. Haris. (2016). Penerapan Asuhan Keperawatan Keluarga dalam Meningkatkan Self Care Behavior Penderita Tuberkulosis Paru di Kota Bima Nusa Tenggara Barat. Jurnal Kesehatan Prima, IO(1), 1579-1587. https://doi.org/10.32807/jkp.v10i1.29

Muhtar, M., \& Aniharyati, A. (2019). Dukungan Pemenuhan Activity Daily Living (ADL) Pada Lanjut Usia di Balai Sosial Lanjut Usia Meci Angi. Bima Nursing Journal, 1(1), 64-69. Retrieved from http://jkp.poltekkes-mataram.ac.id/index.php/bnj/index

Muhtar, M., Haris, A., \& Aniharyati, A. (2019). Penerapan Model Discharge Planning Terstruktur Dan Home Care Dalam Meningkatkan Self Care Penderita Tuberkulosis Paru Di Rumah Sakit Umum Daerah Bima Nusa Tenggara Barat. Buletin Penelitian Sistem Kesehatan, 22(1), 19-26. https://doi.org/10.22435/hsr.v22i1.69

Prabasari, N. A., Juwita, L., \& Maryuti, I. A. (2017). Pengalaman Keluarga Dalam Merawat Lansia Di Rumah (Studi Fenomenologi). Jurnal Ners Lentera, 5(1), 56-68. 
Taviyanda, D., \& Aris Siswanto. (2016). Penerapan Fungsi Afektif Keluarga Pada Lansia Dalam Pemenuhan Activity Daily Living Application. Jurnal Penelitian Keperawatan, 2(2), 144-149. https://doi.org/10.1017/CBO9781107415324.004

Tenforde, M., Jain, A., \& Hickner, J. (2011). The value of personal health records for chronic disease management: what do we know? Family Medicine-Kansas City, 43(5), 351.

Wang, T., \& Dolezel, D. (2016). Usability of Web-based Personal Health Records: An Analysis of Consumers' Perspectives. Perspectives in Health Information Management, 13.

Wulandari, S. T., \& Marliana, Y. (2019). Senam Kebugaran Lansia Memengaruhi Tekanan Darah Pada Wanita Menopause. Jurnal Kesehatan Prima, 13(1), 18-24. 